\title{
Neighborhood Characteristics Associated with the Availability of Alcohol Outlets in Quebec, Canada
}

\author{
André Ngamini Ngui,, ${ }^{1,2}$ Philippe Apparicio, ${ }^{3}$ \\ Mathieu Philibert, ${ }^{4,5}$ and Marie-Josée Fleury ${ }^{1,6}$ \\ ${ }^{1}$ Centre de Réadaptation en Dépendance de Montréal, Institut Universitaire, 950 rue de Louvain Est, \\ Montréal, QC, Canada H2M 2E8 \\ ${ }^{2}$ Centre for Research and Intervention on Suicide and Euthanasia (CRISE), Université du Québec à Montréal, \\ 100 Sherbrooke Street West, Montréal, QC, Canada H2X 3P3 \\ ${ }^{3}$ Spatial Analysis and Regional Economics Laboratory, Université du Québec, Institut National de la Recherche Scientifique, \\ Centre Urbanisation Culture Société, 385 rue Sherbrooke Est, Montréal, QC, Canada H2X 1E3 \\ ${ }^{4}$ Bureau d'Information et d'Études en Santé des Populations, Institut National de Santé Publique du Québec (INSPQ), \\ 190 boulevard Crémazie Est, Montréal, QC, Canada H2P 1E2 \\ ${ }^{5}$ Department of Sexology, Université du Québec à Montréal, C.P. 8888, Succursale Centre-ville, Montréal, QC, Canada H3C 3P8 \\ ${ }^{6}$ Department of Psychiatry, McGill University, Douglas Mental Health University Institute Research Centre, QC, Canada
}

Correspondence should be addressed to André Ngamini Ngui; ngaminingui@gmail.com

Received 17 October 2014; Revised 12 January 2015; Accepted 5 February 2015

Academic Editor: Hervé Kuendig

Copyright (C) 2015 André Ngamini Ngui et al. This is an open access article distributed under the Creative Commons Attribution License, which permits unrestricted use, distribution, and reproduction in any medium, provided the original work is properly cited.

\begin{abstract}
Objectives. The objectives of this study were to examine the spatial accessibility to alcohol outlets in Quebec and to assess the association between neighborhood level characteristics and availability of alcohol outlets. Methods. The Tobit Model was used to assess the association between neighborhood level characteristics and the availability of alcohol outlets within 500, 1000, 2000, and 3000 metres, respectively. Results. Alcohol outlets were found to be most available in the two largest metropolitan areas of the province of Quebec (Montréal and Québec City). Within 1000 metres, alcohol outlets are more available in neighbourhoods with the following characteristics: highest concentration of men, least materially deprived highest concentration of persons aged 20 years or more, and location either in a metropolitan area or in a small town. Finally, the number of bars with video lottery terminals increases with the level of social and material deprivation. Conclusion. In Québec, there is no rule governing the location of alcohol outlets. Thus, there is an abundant literature indicating that the regulation of alcohol outlet density could be an effective means of controlling risk attributable to alcohol consumption.
\end{abstract}

\section{Introduction}

According to the World Health Organization, the global annual consumption of alcoholic beverages per person aged 15 years or older in 2005 was estimated at 6.13 litres of pure alcohol [1]. Recent statistics found that, in 2012, about $17.2 \%$ of Canadians aged 12 and over reported heavy drinking [2] whereas another population-based study indicated that the average number of drinks per week among Canadians was 6.4 (7.9 for men and 4.6 for women) [3]. Alcohol consumption is a social and public health issue because it is responsible for many serious social and developmental issues, including violence, assault, self-inflicted injury and homicide $[4,5]$, child neglect and abuse $[6,7]$, and absenteeism in the workplace $[8,9]$. Alcohol consumption has also been found to be associated with road traffic accidents [1012], a reduction of social capital [13-15], and poor quality of social networks $[16,17]$. Studies consistently show that harmful drinking is a major determinant for neuropsychiatric disorders such as mental health disorders [18], epilepsy [19], and other noncommunicable diseases such as cardiovascular diseases [20-22], cirrhosis of the liver, and various cancers 
$[23,24]$. Alcohol is the world's third largest risk factor for premature mortality (3.2\% of all deaths) and is responsible for approximately $4 \%$ of disability-adjusted life years in the United States [25]. In Québec, it has been reported that 1.8\% of all deaths in 2002 were attributable to alcohol, equivalent to 38,668 life years lost since these deaths occurred mostly among young people. Also, 405,353 episodes of ambulatory care and 48,307 hospitalizations were attributable to alcohol consumption [26].

Greater alcohol outlet density is theoretically and empirically tied to alcohol consumption. One previous study assessing the relationship between alcohol density and the frequent drinking of university and college students, including underage students, found a positive association [27]. Another study reported higher rates of binge drinking among students when there were higher concentrations of alcohol outlets within 1 mile distance of the campus [28]. A meta-analysis conducted by Campbell and colleagues (2009) found a positive association between outlet density and population-level alcohol consumption in five different studies [29]. The association between outlet density and level of alcohol consumption may be explained by the hypothesis that outlet density "affect excessive alcohol consumption and related harms by changing physical access to alcohol (i.e., either increasing or decreasing proximity to alcohol retailers), thus changing the distance that drinkers need to travel to obtain alcohol or to return home after drinking» [29].

There is a growing body of research examining the influence of the neighborhood on accessibility of alcohol outlets [4, 30-32]. A greater density of alcohol outlets in deprived neighborhoods has been found in studies from various countries including European and North American [31, 33-35]. In New Zealand, the positive association between neighborhoods' deprivation and alcohol outlet locations has been found in urban areas but not in rural areas [34]. As markers of local population's socioeconomic status (SES), measures of neighborhood-level deprivation generally describe the composition of local populations in terms of income, education, marital status, living arrangements, and so on. Neighborhood level SES is known to be associated with markers of social disorganization, that is to the nature of social relations (e.g., cohesion) and social capital in their ability to regulate individuals' behaviors $[36,37]$.

However, it is questionable if this association between density of alcohol outlets and deprivation is confounded by other neighborhood characteristics not accounted for (age structure, proportion of immigrants, proportion of people living alone, etc.). Another limitation of these previous studies is that they do not assess the extent to which distance threshold, that is, the distance one is willing to travel to purchase alcohol may influence accessibility to alcohol outlets. Finally, previous studies did not distinguish between types of outlets in the accessibility assessment (e.g., bartavern, restaurant, and grocery).

In Canada in general and in Québec in particular, there is a dearth of studies that have directly assessed the association between neighborhood characteristics and the location of alcohol outlets. There is a clear need to explore which factors in the neighborhood attract alcohol outlets in order to control the negative impacts of alcohol outlet locations in the communities. For instance, by controlling the attribution of liquor permits in the neighborhoods in which are located atrisk populations.

The present study had two objectives: (1) to examine the spatial accessibility to alcohol outlets in Québec and (2) to assess the association between neighborhood level characteristics and access to alcohol outlets in general and by type of outlet.

\section{Methods}

2.1. Study Location. This research involves the entire province of Québec (Canada) with an area of $1542056 \mathrm{~km}^{2}$ and about 8.18 million inhabitants at the end of 2013 [38]. In Québec, alcohol can be sold either in outlets administered by the government (Société des Alcohols du Québec (SAQ)) or in private outlets licensed by the Régie des alcools, des courses et des jeux (RACJ). The RACJ is responsible for administering the Act respecting liquor permits as well as the Act respecting lotteries, publicity contests, and amusement machines. Those who have an alcohol permit can obtain a permit to operate video lottery terminals (VLT). In fact, applicants for a license for video lottery terminals must first possess a license to operate a bar, pub, or tavern [39]. Conversely, all outlets with VTL possess liquor license and sell alcohol, although not all alcohol outlets possess VLT. The register of liquor licenses also includes the type of outlet. The websites of both SAQ and RACJ contain the geographic information (i.e., street address, municipality, and postal code) on the location of each alcohol outlet.

2.2. Data Collection Procedure. In November 2013, we accessed the constantly updated websites of RACJ and SAQ from which listings of alcohol outlets were extracted. In total, the database included 19,620 business addresses, of which 270 (1.4\%) were removed because they could not be geocoded. It is worth noting that multiple outlets could be located at the same address, for example, a restaurant and a bar. Finally, the 19,350 geocoded addresses (98.6\%) contain 24,190 outlets classified in six categories: (1) SAQ outlets $(n=400)$, (2) bars/breweries/taverns ( $n=5,726),(3)$ bars with video lottery terminals ( $n=1,991)$, (4) restaurants $(n=7,782)$; (5) offpremise (off-premise outlets are not administered by SAQ) ( $n=7,605)$, and (6) others (retailers, wholesalers, cider sellers, etc.) $(n=686)$. Alcohol outlets were geocoded using the $(x, y)$ coordinates of residential or commercial property parcel points.

2.3. Area-Level Characteristics. Neighborhood characteristics were obtained from the 2006 Canadian census at the level of the dissemination area (DA) which is the smallest census unit for which socioeconomic and demographic data are disseminated $($ mean $=583$ inhabitants; $S D=368$ ) [40]. Neighborhoods were described in terms of gender composition (percentage of males), ethnic composition (percentage of recent immigrants; i.e., immigrants who arrived in Canada in the last five years), residential instability (percentage of 
individuals who moved during the last year), age composition (percentage of individuals by age group), area-level socioeconomic status, and an urban-rural denomination.

Area-level socioeconomic status was operationalized using a deprivation index obtained from a principal component analysis consisting of six census variables, which lead to two factors: material and social deprivation [41, 42]. Material deprivation is mainly associated with average income, the unemployment rate and the proportion of persons without a high school diploma. Social deprivation is mostly correlated with the proportion of single-parent families, the proportion of people living alone, and the proportion of persons who are separated, divorced, or widowed. For the purpose of this study, DAs were classified into population weighted quintiles on each type of deprivation, the first quintile representing the least deprived group.

DAs were also categorized based on an urban-rural denomination produced by Statistics Canada. A modification of the Statistical Area Classification (SAC) [43] led to a threelevel categorization: metropolitan areas (municipalities with an urban core population $\geq 100,000$ inhabitants), agglomerations (municipalities with a population ranging from 10,000 to 100,000 inhabitants), and rural areas (municipalities with less than 10,000 inhabitants) [44].

2.4. Data Analysis. Geographic accessibility was operationalized by the number of alcohol outlets located within a given distance. We used different threshold measures $(500,1000$, 2000, and 3000 metres) and this was done for each type of alcohol outlet considered separately as well as for all outlets together. All accessibility measures were first computed at the street block level and then aggregated at the DA level (street blocks are nested within Das) using the population-weighted average number of outlets of each census block. Compared to accessibility measured at the DA level directly, this helped to avoid aggregation errors [45]. For example, the number of alcohol outlets within one kilometre for $\mathrm{DA}_{i}$ is obtained as follows:

$$
A_{\mathrm{DA}_{i}}=\frac{\sum_{b \in i} W_{b} \sum_{j \in S} S_{j}}{\sum_{b \in i} W_{b}},
$$

where $W_{b}$ is the total population of census block $b$ within $\mathrm{DA}_{i}$ and $S_{j}$ represents the number of alcohol outlets within 1000 metres of block $b$. All distances were computed in ArcGIS using the network analyst extension and the road network was provided by Adresses Québec [46].

Next, the Tobit Model was used to assess the association between neighborhood level characteristics and accessibility measures to alcohol outlets in general and by type of outlet. The Poisson regression model is often used with count data. Here, however, such a model was not suitable as the number of outlets had decimal parts due to the aggregation from block-level frequencies to DA-level frequencies of outlets. Considering the large number of DAs with no alcohol outlet, it was difficult to use a standard ordinary least squares (OLS) regression to examine neighborhood characteristics associated with the number of outlets because a simple OLS is likely to yield inconsistent and biased results in such a situation $[47,48]$. Because the OLS estimators are always biased downward [49], it has been suggested that applying it to the positive observations is not a satisfactory solution since it does not solve the problem of inconsistency. It would rather introduce an element of selection bias [50]. Therefore, a left censoring mechanism with a minimum value of 0 alcohol outlet was introduced. To account for this censoring, the Tobit regression model (with the SAS QLIM procedure) is used with the number of alcohol outlets available as the response variable. The analyses were weighted by the 2006 total population of each DA. Before proceeding with multivariate analyses, all variables were screened for statistical assumption violations, as well as for missing values and outliers. The correlation coefficient was tested between all variables to avoid multicollinearity in the model [51].

\section{Results}

3.1. Availability of Alcohol Outlets in the Immediate Surroundings. Table 1 presents the number of alcohol outlets available within 500, 1000, 2000, and 3000 metres by DA. The average number of alcohol outlets varied from 4.20 within 500 metres to $15.94,55.68$, and 114.60 within one, two, and three kilometres, respectively. Moreover, within 500 metres, $25 \%$ of the DAs have 3.75 or more alcohol outlets (see the third quartile). The results also indicate that there are more restaurants and off-premise outlets with alcohol permits whatever the threshold distance. Within 500 metres, there is a mean of 1.52 restaurants, 1.46 off-premise outlets and $.71 \mathrm{bar} /$ brewery or tavern available at 500 metres, and these numbers increase significantly to $20.71,17.89$, and 10.11 at 2 kilometres to reach $43.09,36.31$, and 21.07, respectively, at 3 kilometres.

For reasons of brevity, we only present the spatial distribution of one accessibility measure, that is, the number of alcohol outlets located within one kilometre of a given DA (Figure 1). It is not surprising that highest values are observed in the two largest metropolitan areas of the province of Québec (Montreal and Québec City). It should be noted that similar spatial patterns are observed for each type of alcohol outlet and each distance threshold (not shown).

\subsection{Neighborhood Factors Associated with the Availability of} All Types of Alcohol Outlets. Table 2 presents the association between neighborhood characteristics and the availability of alcohol outlets in the DAs by distance and type of outlet. All factors were associated with location of outlets, which is due to the high statistical power resulting from the almost complete coverage of our datasets combined with the robustness of the Tobit model [52]. At the threshold of $1 \mathrm{~km}$, a one-percent increase in the number of persons aged between 20 and 34 years is associated with an increase of $3.39(P<.0001)$ alcohol outlets in general whereas the number of alcohol outlets increases to $1.95(P<.0001)$ for each one percent increase in the number of persons aged 35-44 in the DA. Within $1 \mathrm{~km}$, the first quintile of material deprivation (least deprived) has $5.89(P<.0001)$ more alcohol outlets in comparison with the fifth quintile (most 
TABLE 1: Descriptive statistics of accessibility to alcohol outlets in Québec ( $N=12,712$ DAs).

\begin{tabular}{|c|c|c|c|c|c|c|c|}
\hline & All & SAQ & $\begin{array}{l}\text { Bar/brewery/ } \\
\text { tavern }\end{array}$ & $\begin{array}{l}\text { Bar with video } \\
\text { lottery terminal }\end{array}$ & Restaurant & Off-premise & Other types \\
\hline \multicolumn{8}{|l|}{500 metres } \\
\hline Mean & 4.20 & .05 & .71 & .38 & 1.52 & 1.46 & .09 \\
\hline $\mathrm{SD}$ & 10.23 & .20 & 2.64 & .96 & 4.95 & 2.67 & .32 \\
\hline Kurtosis & 51.52 & 21.37 & 160.95 & 31.47 & 58.67 & 12.17 & 81.08 \\
\hline Skewness & 5.95 & 4.44 & 10.26 & 4.61 & 6.75 & 3.16 & 6.98 \\
\hline Quartile 1 & .02 & .00 & .00 & .00 & .00 & .00 & .00 \\
\hline Median & .88 & .00 & .00 & .00 & .00 & .39 & .00 \\
\hline Quartile 3 & 3.75 & .00 & .46 & .25 & 1.00 & 1.61 & .00 \\
\hline Maximum & 196.00 & 2.00 & 75.00 & 14.00 & 87.00 & 27.00 & 6.71 \\
\hline \multicolumn{8}{|l|}{1 kilometre } \\
\hline Mean & 15.94 & .22 & 2.87 & 1.43 & 5.81 & 5.27 & .34 \\
\hline $\mathrm{SD}$ & 35.00 & .48 & 9.37 & 2.66 & 16.56 & 8.59 & .79 \\
\hline Kurtosis & 35.95 & 11.66 & 82.39 & 13.99 & 43.01 & 8.75 & 37.13 \\
\hline Skewness & 5.35 & 2.91 & 8.24 & 3.27 & 6.06 & 2.84 & 4.77 \\
\hline Quartile 1 & 1.00 & .00 & .00 & .00 & .00 & .43 & .00 \\
\hline Median & 4.89 & .00 & .61 & .22 & 1.00 & 2.00 & .00 \\
\hline Quartile 3 & 15.81 & .09 & 2.25 & 1.76 & 4.46 & 5.67 & .28 \\
\hline Maximum & 385.00 & 5.00 & 138.43 & 24.00 & 190.00 & 61.50 & 10.00 \\
\hline \multicolumn{8}{|l|}{2 kilometres } \\
\hline Mean & 55.68 & .83 & 10.11 & 4.97 & 20.71 & 17.89 & 1.18 \\
\hline $\mathrm{SD}$ & 112.11 & 1.26 & 28.04 & 7.90 & 52.20 & 28.52 & 2.01 \\
\hline Kurtosis & 30.19 & 16.06 & 68.85 & 9.40 & 38.06 & 8.29 & 19.48 \\
\hline Skewness & 4.87 & 3.29 & 7.41 & 2.86 & 5.62 & 2.80 & 3.66 \\
\hline Quartile 1 & 5.06 & .00 & .81 & .12 & 1.00 & 2.00 & .00 \\
\hline Median & 21.00 & .47 & 3.19 & 2.00 & 5.62 & 7.21 & .22 \\
\hline Quartile 3 & 57.32 & 1.00 & 9.04 & 6.00 & 17.40 & 18.44 & 2.00 \\
\hline Maximum & 1248.14 & 12.00 & 420.00 & 60.00 & 605.11 & 172.00 & 20.00 \\
\hline \multicolumn{8}{|l|}{3 kilometres } \\
\hline Mean & 114.60 & 1.71 & 21.07 & 10.06 & 43.09 & 36.31 & 2.36 \\
\hline $\mathrm{SD}$ & 223.19 & 2.41 & 52.70 & 15.80 & 101.64 & 59.01 & 3.59 \\
\hline Kurtosis & 20.50 & 11.47 & 41.90 & 7.63 & 26.76 & 7.88 & 12.56 \\
\hline Skewness & 4.16 & 2.96 & 5.95 & 2.72 & 4.81 & 2.77 & 3.06 \\
\hline Quartile 1 & 10.00 & .00 & 1.98 & .93 & 2.14 & 3.60 & .00 \\
\hline Median & 43.34 & 1.00 & 7.60 & 4.22 & 12.83 & 14.32 & 1.00 \\
\hline Quartile 3 & 112.86 & 2.00 & 18.64 & 11.54 & 37.11 & 36.35 & 3.00 \\
\hline Maximum & 1857.00 & 18.00 & 540.00 & 94.00 & 911.00 & 339.63 & 28.00 \\
\hline
\end{tabular}

deprived). In contrast, social deprivation tends to be inversely associated with the number of alcohol outlets. The findings of Table 2 confirm the highest concentration of alcohol outlets in metropolitan and small towns compared to rural areas. At $1 \mathrm{~km}$ for instance, there are 5.07 and 4.44 more alcohol outlets in general respectively in metropolitan areas and small towns than in rural areas. Moreover, the percentage of immigrants in the total population of the DA is also associated positively with all alcohol outlets $(\beta=.43, P<.0001)$. Globally, the associations observed at 2 and 3 kilometres are similar but stronger.
3.3. Neighborhood Factors Associated with Availability of Specific Types of Alcohol Outlets. As shown in Table 2, at 3 kilometres, metropolitan areas $(\beta=1.66, P<.0001)$ and less materially deprived neighborhoods $(\beta=1.23, P<.0001)$ are more correlated with the SAQ. However, a one-percent increase in the number of immigrants is associated with an increase of $1.54(P<.0001)$ restaurants and $1.08(P<.0001)$ off-premise outlets. Compared to rural areas, there are more bars/breweries in small towns and in metropolitan areas at 2 kilometres with $6.24(P<.0001)$ and $4.72(P<.0001)$ outlets, respectively. At the same threshold, there are also 


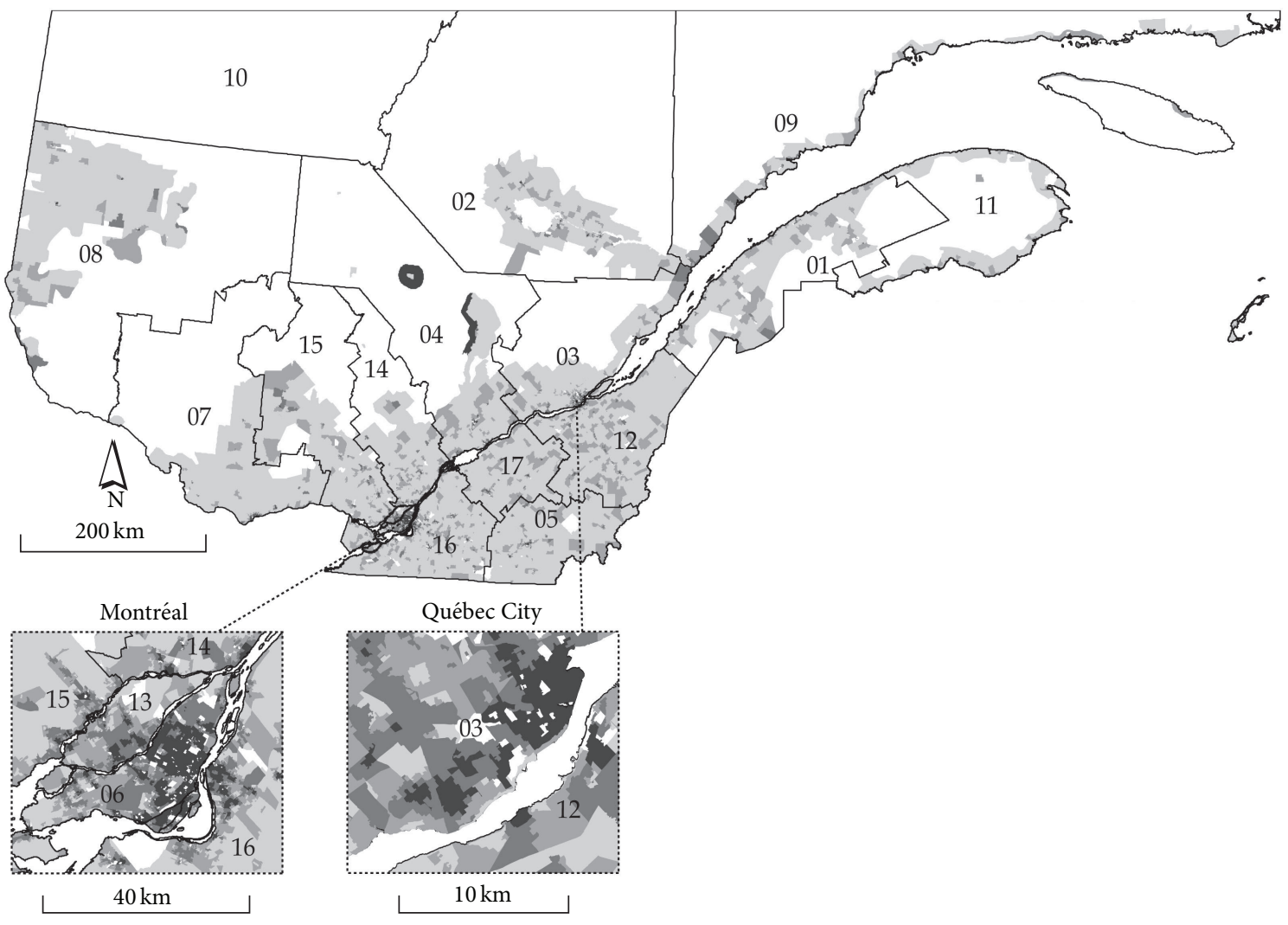

Number of alcohol outlets within a network distance of one kilometre by dissemination area

0.00 to 1.00
1.01 to 4.89
4.90 to 15.81
15.82 to 385.00

Administrative region

(01) Bas-Saint-Laurent
(02) Saguenay-Lac-Saint-Jean
(03) Capitale-Nationale
(04) Mauricie
(05) Estrie
(06) Montréal

(07) Qutaouais

(08) Abitibi-Témiscamingue

(09) Côte-Nord

(10) Nord-du-Québec

(11) Gaspésie-Îles-de-la-Madeleine

(12) Chaudière-Appalaches

FIGURE 1: Spatial locations of alcohol outlets in Québec.

more bars with video lottery terminal in metropolitan and small towns than in rural remotes with $4.56(P<.0001)$ and $3.57(P<.0001)$ outlets, respectively.

Accessibility to alcohol outlets was associated linearly with the level of neighborhood deprivation. At 2 kilometres for instance, accessibility to alcohol outlets was highest in least materially deprived neighborhoods $(\beta=30.87)$ and lowest in the highest material deprived neighborhood $(\beta=-3.92)$. Inversely, high socially deprived neighborhoods tended to be more accessible to alcohol outlets $(\beta=-6.52)$ than least socially deprived neighborhoods $(\beta=-21.61)$.

At 2 kilometres, every one percentage increase in the number of immigrants in a neighborhood increases the number of off-premise outlets by $.48(P<.0001)$. The number of off-premise outlets also increases for every one percent increase in each age group except for $15-19$ years: 2.55 $(P<.0001)$ for $20-34$ years; $1.88(P<.0001)$ for $35-44$ years; $.87(P<.0001)$ for $45-64$ years; and $1.24(P<.0001)$ for 65 years and over.

The association between off-premise outlets and materially deprived DAs seems more complex. At 500 metres, the most affluent DAs tend to be less attractive and the number of off-premise outlets tends to increase gradually with the level of material deprivation (from $\beta=-1.36$ to $\beta=-.58$ ). As the distance threshold increases, the relation is reverse so that, at 3 Kilometres, more off-premise outlets in the most affluent DAs compare with more deprived (from $\beta=.48$ to $\beta=-4.44$ ). This apparent paradoxical situation may be explained by the fact that (1) as the distance increases, the suburbs are included in the analyses and (2) most of the time, off-premise outlets are included in supermarkets which tend to locate mostly in central cities to be closer to the high concentration of the population.

The association between materially deprived DAs and bars with VLT tends to follow the same pattern as the location of off-premise outlets. Generally, bars with VLT tend to be concentrated in the downtown area and in pericentral districts with the highest population density.

Finally, whatever the distance threshold, it is important to note that the number of bars with video lottery terminals increases with the level of social deprivation. In other words, 
TABLE 2: Weighted Tobit results for neighborhood factors associated with the availability of alcohol outlets*.

\begin{tabular}{|c|c|c|c|c|c|c|c|}
\hline & $\begin{array}{c}\text { All } \\
\beta(\mathrm{SE}) \\
\end{array}$ & $\begin{array}{l}\text { SAQ } \\
\beta(\mathrm{SE}) \\
\end{array}$ & $\begin{array}{c}\text { Bar/brewery/ } \\
\text { tavern } \\
\beta(\mathrm{SE})\end{array}$ & $\begin{array}{c}\text { Bar with video } \\
\text { lottery terminal } \\
\beta(\mathrm{SE})\end{array}$ & $\begin{array}{c}\text { Restaurant } \\
\beta(\mathrm{SE}) \\
\end{array}$ & $\begin{array}{c}\text { Off-premise } \\
\qquad \beta(\mathrm{SE})\end{array}$ & $\begin{array}{c}\text { Other types } \\
\beta(\mathrm{SE})\end{array}$ \\
\hline \multicolumn{8}{|c|}{500 metres } \\
\hline Intercept & $-67.26(.11)$ & $-3.79(.02)$ & $-27.15(.05)$ & $-8.71(.02)$ & $-39.49(.08)$ & $-12.75(.03)$ & $-4.12(.02)$ \\
\hline$\%$ male & $.42(.00)$ & $-.01(.00)$ & $.19(.00)$ & $.05(.00)$ & $.20(.00)$ & $.04(.00)$ & $.01(.00)$ \\
\hline$\% 15-19$ years & $.17(.00)$ & $.02(.00)$ & $.08(.00)$ & $.01(.00)$ & $.02(.00)$ & $.02(.00)$ & $-.01(.00)$ \\
\hline$\% 20-34$ years & $1.06(.00)$ & $.05(.00)$ & $.33(.00)$ & $.12(.00)$ & $.59(.00)$ & $.27(.00)$ & $.05(.00)$ \\
\hline$\% 35-44$ years & $.61(.00)$ & $.03(.00)$ & $.18(.00)$ & $.07(.00)$ & $.33(.00)$ & $.16(.00)$ & $.03(.00)$ \\
\hline$\% 45-64$ years & $.33(.00)$ & $.02(.00)$ & $.12(.00)$ & $.04(.00)$ & $.22(.00)$ & $.07(.00)$ & $.02(.00)$ \\
\hline$\% 65$ years+ & $.64(.00)$ & $.04(.00)$ & $.25(.00)$ & $.09(.00)$ & $.38(.00)$ & $.14(.00)$ & $.04(.00)$ \\
\hline$\%$ mobility & $.00(.00)$ & $.00(.00)$ & $.02(.00)$ & $.00(.00)$ & $.01(.00)$ & $-.02(.00)$ & $.00(.00)$ \\
\hline$\%$ immigrants & $.12(.00)$ & $.00(.00)$ & $.02(.00)$ & $.02(.00)$ & $.08(.00)$ & $.04(.00)$ & $.00(.00)$ \\
\hline \multicolumn{8}{|l|}{ Material deprivation } \\
\hline 1st quintile & $-.75(.01)$ & $.21(.00)$ & $-.07(.01)$ & $-1.19(.00)$ & $.69(.01)$ & $-1.36(.00)$ & $-.17(.00)$ \\
\hline 2nd quintile & $-2.03(.01)$ & $.06(.00)$ & $-.72(.01)$ & $-.84(.00)$ & $-.45(.01)$ & $-1.2(.00)$ & $-.19(.00)$ \\
\hline 3rd quintile & $-1.8(.01)$ & $.02(.00)$ & $-.47(.01)$ & $-.52(.00)$ & $-.47(.01)$ & $-.88(.00)$ & $-.15(.00)$ \\
\hline 4th quintile & $-1.32(.01)$ & $.00(.00)$ & $-.36(.01)$ & $-.33(.00)$ & $-.38(.01)$ & $-.58(.00)$ & $.00(.00)$ \\
\hline 5th quintile & Reference & Reference & Reference & Reference & Reference & Reference & Reference \\
\hline \multicolumn{8}{|l|}{ Social deprivation } \\
\hline 1st quintile & $-2.95(.02)$ & $-.23(.00)$ & $-1.40(.01)$ & $-1.09(.00)$ & $-1.93(.01)$ & $-1.38(.00)$ & $-.58(.00)$ \\
\hline 2nd quintile & $-2.62(.01)$ & $-.26(.00)$ & $-1.18(.01)$ & $-.90(.00)$ & $-1.48(.01)$ & $-1.18(.00)$ & $-.49(.00)$ \\
\hline 3rd quintile & $-1.4(.01)$ & $-.04(.00)$ & $-.52(.01)$ & $-.47(.00)$ & $-.6(.01)$ & $-.75(.00)$ & $-.31(.00)$ \\
\hline 4th quintile & $.01(.01)$ & $.02(.00)$ & $.06(.01)$ & $-.08(.00)$ & $.27(.01)$ & $-.16(.00)$ & $-.03(.00)$ \\
\hline 5th quintile & Reference & Reference & Reference & Reference & Reference & Reference & Reference \\
\hline \multicolumn{8}{|l|}{ Location of the DA } \\
\hline Metropolitan area & $1.09(.01)$ & $-.03(.00)$ & $-.71(.01)$ & $.41(.00)$ & $-.14(.01)$ & $.84(.00)$ & $.01(.00)$ \\
\hline Small town & $.98(.01)$ & $-.16(.00)$ & $.26(.01)$ & $.34(.00)$ & $-.18(.01)$ & $.32(.00)$ & $.21(.00)$ \\
\hline Rural & Reference & Reference & Reference & Reference & Reference & Reference & Reference \\
\hline \multicolumn{8}{|c|}{1 KILOMETRE } \\
\hline Intercept & $-214.62(.32)$ & $-3.42(.01)$ & $-75.14(.12)$ & $-17.56(.03)$ & $-110.19(.18)$ & $-36.48(.07)$ & $-6.31(.02)$ \\
\hline$\%$ Male & $1.42(.00)$ & $-.01(.00)$ & $.58(.00)$ & $.09(.00)$ & $.60(.00)$ & $.10(.00)$ & $.01(.00)$ \\
\hline$\% 15-19$ years & $.52(.01)$ & $.02(.00)$ & $.32(.00)$ & $.05(.00)$ & $.22(.00)$ & $.03(.00)$ & $.02(.00)$ \\
\hline$\% 20-34$ years & $3.39(.00)$ & $.07(.00)$ & $.97(.00)$ & $.27(.00)$ & $1.67(.00)$ & $.81(.00)$ & $.10(.00)$ \\
\hline$\%$ 35-44 years & $1.95(.01)$ & $.03(.00)$ & $.40(.00)$ & $.18(.00)$ & $.96(.00)$ & $.55(.00)$ & $.05(.00)$ \\
\hline$\% 45-64$ years & $1.09(.00)$ & $.03(.00)$ & $.34(.00)$ & $.09(.00)$ & $.61(.00)$ & $.25(.00)$ & $.04(.00)$ \\
\hline$\% 65$ years + & $1.87(.00)$ & $.04(.00)$ & $.64(.00)$ & $.19(.00)$ & $.97(.00)$ & $.40(.00)$ & $.06(.00)$ \\
\hline$\%$ mobility & $-.08(.00)$ & $.00(.00)$ & $.04(.00)$ & $-.02(.00)$ & $.00(.00)$ & $-.07(.00)$ & $.00(.00)$ \\
\hline$\%$ immigrants & $.43(.00)$ & $.01(.00)$ & $.08(.00)$ & $.04(.00)$ & $.23(.00)$ & $.13(.00)$ & $.02(.00)$ \\
\hline \multicolumn{8}{|l|}{ Material deprivation } \\
\hline 1st Quintile & $5.89(.04)$ & $.31(.00)$ & $2.43(.02)$ & $-1.42(.00)$ & $5.65(.02)$ & $-1.86(.01)$ & $-.16(.00)$ \\
\hline 2nd Quintile & $-.60(.04)$ & $.10(.00)$ & $-.12(.01)$ & $-1.14(.00)$ & $1.79(.02)$ & $-1.92(.01)$ & $-.20(.00)$ \\
\hline 3rd Quintile & $-1.53(.04)$ & $.05(.00)$ & $.08(.01)$ & $-.61(.00)$ & $.79(.02)$ & $-1.43(.01)$ & $-.13(.00)$ \\
\hline 4th Quintile & $-1.86(.04)$ & $.06(.00)$ & $-.04(.01)$ & $-.38(.00)$ & $.39(.02)$ & $-1.00(.01)$ & $.00(.00)$ \\
\hline 5th Quintile & Reference & Reference & Reference & Reference & Reference & Reference & Reference \\
\hline \multicolumn{8}{|l|}{ Social deprivation } \\
\hline 1st Quintile & $-6.47(.05)$ & $-.31(.00)$ & $-2.47(.02)$ & $-1.83(.01)$ & $-3.11(.03)$ & $-3.21(.01)$ & $-.72(.00)$ \\
\hline 2nd Quintile & $-7.22(.04)$ & $-.35(.00)$ & $-2.11(.02)$ & $-1.49(.00)$ & $-3.08(.02)$ & $-3.2(.01)$ & $-.59(.00)$ \\
\hline 3rd Quintile & $-5.11(.04)$ & $-.22(.00)$ & $-1.15(.02)$ & $-.89(.00)$ & $-1.74(.02)$ & $-2.26(.01)$ & $-.39(.00)$ \\
\hline
\end{tabular}


TABLE 2: Continued.

\begin{tabular}{|c|c|c|c|c|c|c|c|}
\hline & $\begin{array}{c}\text { All } \\
\beta(\mathrm{SE})\end{array}$ & $\beta(\mathrm{SE})$ & $\begin{array}{c}\text { Bar/brewery/ } \\
\text { tavern } \\
\beta(\mathrm{SE})\end{array}$ & $\begin{array}{c}\text { Bar with video } \\
\text { lottery terminal } \\
\beta(\mathrm{SE})\end{array}$ & $\begin{array}{c}\text { Restaurant } \\
\beta(\mathrm{SE})\end{array}$ & $\begin{array}{c}\text { Off-premise } \\
\qquad \beta(\mathrm{SE})\end{array}$ & $\begin{array}{c}\text { Other types } \\
\beta(\mathrm{SE})\end{array}$ \\
\hline 4th Quintile & $-.58(.04)$ & $.02(.00)$ & $.22(.01)$ & $-.14(.00)$ & $.39(.02)$ & $-.54(.01)$ & $-.02(.00)$ \\
\hline 5th Quintile & Reference & Reference & Reference & Reference & Reference & Reference & Reference \\
\hline \multicolumn{8}{|l|}{ Location of the DA } \\
\hline Metropolitan area & $5.07(.04)$ & $.16(.00)$ & $.16(.01)$ & $1.49(.00)$ & $1.51(.02)$ & $2.99(.01)$ & $.49(.00)$ \\
\hline Small town & $4.44(.04)$ & $-.06(.00)$ & $1.85(.02)$ & $1.19(.00)$ & $1.27(.02)$ & $1.21(.01)$ & $.67(.00)$ \\
\hline Rural & Reference & Reference & Reference & Reference & Reference & Reference & Reference \\
\hline \multicolumn{8}{|c|}{2 KILOMETRE } \\
\hline Intercept & $-684.36(.95)$ & $-6.92(.02)$ & $-197.52(.29)$ & $-38.76(.08)$ & $-329.61(.49)$ & $-123.08(.22)$ & $-12.53(.03)$ \\
\hline$\%$ Male & $4.86(.01)$ & $.00(.00)$ & $1.56(.00)$ & $.13(.00)$ & $2.13(.01)$ & $.42(.00)$ & $.02(.00)$ \\
\hline$\% 15-19$ years & $.74(.02)$ & $.06(.00)$ & $.79(.01)$ & $.09(.00)$ & $.67(.01)$ & $-.14(.01)$ & $.06(.00)$ \\
\hline$\% 20-34$ years & $1.45(.01)$ & $.13(.00)$ & $2.49(.00)$ & $.7(.00)$ & $4.86(.01)$ & $2.55(.00)$ & $.2(.00)$ \\
\hline$\% 35-44$ years & $6.43(.02)$ & $.07(.00)$ & $1.25(.01)$ & $.48(.00)$ & $2.89(.01)$ & $1.88(.00)$ & $.12(.00)$ \\
\hline$\%$ 45-64 years & $3.62(.01)$ & $.05(.00)$ & $.97(.00)$ & $.25(.00)$ & $1.72(.00)$ & $.87(.00)$ & $.09(.00)$ \\
\hline$\% 65$ years + & $5.59(.01)$ & $.08(.00)$ & $1.52(.00)$ & $.41(.00)$ & $2.6(.00)$ & $1.24(.00)$ & $.12(.00)$ \\
\hline$\%$ mobility & $-.47(.01)$ & $.00(.00)$ & $.05(.00)$ & $-.06(.00)$ & $-.1(.00)$ & $-.26(.00)$ & $0(.00)$ \\
\hline$\%$ immigrants & $1.60(.00)$ & $.03(.00)$ & $.27(.00)$ & $.15(.00)$ & $.76(.00)$ & $.48(.00)$ & $.05(.00)$ \\
\hline \multicolumn{8}{|l|}{ Material deprivation } \\
\hline 1st Quintile & $28.30(.12)$ & $.66(.00)$ & $1.95(.04)$ & $-.89(.01)$ & $22.72(.06)$ & $-1.28(.03)$ & $.34(.00)$ \\
\hline 2nd Quintile & $4.40(.11)$ & $.27(.00)$ & $3.51(.03)$ & $-.91(.01)$ & $8.44(.06)$ & $-3.23(.03)$ & $-.06(.00)$ \\
\hline 3rd Quintile & $1.57(.11)$ & $.23(.00)$ & $2.38(.03)$ & $-.27(.01)$ & $5.42(.06)$ & $-1.98(.03)$ & $.02(.00)$ \\
\hline 4th Quintile & $-3.76(.11)$ & $.12(.00)$ & $.67(.03)$ & $-.25(.01)$ & $1.06(.06)$ & $-2.04(.02)$ & $.05(.00)$ \\
\hline 5th Quintile & Reference & Reference & Reference & Reference & Reference & Reference & Reference \\
\hline \multicolumn{8}{|l|}{ Social deprivation } \\
\hline 1st Quintile & $-2.66(.14)$ & $-.44(.00)$ & $-5.14(.04)$ & $-3.26(.01)$ & $-6.78(.07)$ & $-9.29(.03)$ & $-.9(.00)$ \\
\hline 2nd Quintile & $-26.46(.13)$ & $-.57(.00)$ & $-6.08(.04)$ & $-3.25(.01)$ & $-9.86(.07)$ & $-1.43(.03)$ & $-.91(.00)$ \\
\hline 3rd Quintile & $-2.88(.12)$ & $-.43(.00)$ & $-4.54(.04)$ & $-2.21(.01)$ & $-7.07(.06)$ & $-8.26(.03)$ & $-.61(.00)$ \\
\hline 4th Quintile & $-5.88(.11)$ & $-.05(.00)$ & $-.74(.03)$ & $-.35(.01)$ & $-1.05(.06)$ & $-2.86(.03)$ & $-.1(.00)$ \\
\hline 5th Quintile & Reference & Reference & Reference & Reference & Reference & Reference & Reference \\
\hline \multicolumn{8}{|l|}{ Location of the DA } \\
\hline Metropolitan area & 17.55 & $.78(.00)$ & $4.72(.03)$ & $4.56(.01)$ & $7.16(.06)$ & $9.11(.03)$ & $1.48(.00)$ \\
\hline Small town & $12.38(.13)$ & $.32(.00)$ & $6.24(.04)$ & $3.57(.01)$ & $6(.07)$ & $3.06(.03)$ & $1.72(.00)$ \\
\hline Rural & Reference & Reference & Reference & Reference & Reference & Reference & Reference \\
\hline \multicolumn{8}{|c|}{3 KILOMETRE } \\
\hline Intercept & $-1335.6(1.81)$ & $-12.14(.02)$ & $-364.31(.50)$ & $-68.76(.14)$ & $-645.96(.90)$ & $-244.6(.45)$ & $-19.10(.04)$ \\
\hline$\%$ Male & $90.57(.03)$ & $.02(.00)$ & $2.90(.01)$ & $.16(.00)$ & $4.48(.01)$ & $.98(.01)$ & $.04(.00)$ \\
\hline$\% 15-19$ years & $.43(.04)$ & $.07(.00)$ & $.97(.01)$ & $.06(.00)$ & $.96(.02)$ & $-.61(.01)$ & $.07(.00)$ \\
\hline$\%$ 20-34 years & $2.77(.02)$ & $.22(.00)$ & $4.81(.01)$ & $1.34(.00)$ & $9.49(.01)$ & $5.00(.00)$ & $.32(.00)$ \\
\hline$\%$ 35-44 years & $12.88(.03)$ & $.13(.00)$ & $2.59(.01)$ & $.98(.00)$ & $5.76(.02)$ & $3.65(.01)$ & $.18(.00)$ \\
\hline$\%$ 45-64 years & $6.97(.02)$ & $.08(.00)$ & $1.74(.00)$ & $.47(.00)$ & $3.21(.01)$ & $1.67(.00)$ & $.12(.00)$ \\
\hline$\% 65$ years + & $1.79(.02)$ & $.13(.00)$ & $2.73(.00)$ & $.72(.00)$ & $4.96(.01)$ & $2.41(.00)$ & $.18(.00)$ \\
\hline$\%$ mobility & $-1.23(.01)$ & $.00(.00)$ & $.00(.00)$ & $-.14(.00)$ & $-.32(.00)$ & $-.57(.00)$ & $-.01(.00)$ \\
\hline$\%$ immigrants & $3.42(.00)$ & $.06(.00)$ & $.50(.00)$ & $.32(.00)$ & $1.54(.00)$ & $1.08(.00)$ & $.09(.00)$ \\
\hline \multicolumn{8}{|l|}{ Material deprivation } \\
\hline 1st Quintile & $57.14(.22)$ & $1.23(.00)$ & $21.33(.06)$ & $-.14(.02)$ & $42.49(.11)$ & $.48(.06)$ & $.97(.00)$ \\
\hline 2nd Quintile & $6.21(.22)$ & $.53(.00)$ & $6.71(.06)$ & $-1.02(.02)$ & $14.60(.11)$ & $-5.35(.05)$ & $.20(.00)$ \\
\hline
\end{tabular}


TABLE 2: Continued.

\begin{tabular}{|c|c|c|c|c|c|c|c|}
\hline & $\begin{array}{c}\text { All } \\
\beta(\mathrm{SE}) \\
\end{array}$ & $\beta(\mathrm{SE})$ & $\begin{array}{c}\text { Bar/brewery/ } \\
\text { tavern } \\
\beta(\mathrm{SE})\end{array}$ & $\begin{array}{c}\text { Bar with video } \\
\text { lottery terminal } \\
\beta(\mathrm{SE})\end{array}$ & $\begin{array}{c}\text { Restaurant } \\
\beta(\mathrm{SE})\end{array}$ & $\begin{array}{c}\text { Off-premise } \\
\beta(\mathrm{SE})\end{array}$ & $\begin{array}{c}\text { Other types } \\
\beta(\mathrm{SE})\end{array}$ \\
\hline 3rd Quintile & $1.18(.21)$ & $.39(.00)$ & $4.23(.06)$ & $-.22(.02)$ & $8.90(.10)$ & $-3.63(.05)$ & $.22(.00)$ \\
\hline 4th Quintile & $-10.03(.20)$ & $.16(.00)$ & $.75(.06)$ & $-.63(.02)$ & $.79(.10)$ & $-4.44(.05)$ & $.05(.00)$ \\
\hline 5th Quintile & Reference & Reference & Reference & Reference & Reference & Reference & Reference \\
\hline \multicolumn{8}{|l|}{ Social deprivation } \\
\hline 1st Quintile & $-35.42(.26)$ & $-.56(.00)$ & $-7.17(.07)$ & $-5.25(.02)$ & $-1.54(.13)$ & $-16.79(.07)$ & $-1.16(.01)$ \\
\hline 2nd Quintile & $-49.17(.25)$ & $-.79(.00)$ & $-9.79(.07)$ & $-5.48(.02)$ & $-17.29(.12)$ & $-19.56(.06)$ & $-1.3(.01)$ \\
\hline 3rd Quintile & $-4.43(.23)$ & $-.59(.00)$ & $-7.97(.06)$ & $-4.02(.02)$ & $-13.51(.11)$ & $-15.87(.06)$ & $-.93(.01)$ \\
\hline 4th Quintile & $-1.46(.21)$ & $-.05(.00)$ & $-1.27(.06)$ & $-.61(.02)$ & $-2.05(.10)$ & $-5.55(.05)$ & $-.13(.00)$ \\
\hline 5th Quintile & Reference & Reference & Reference & Reference & Reference & Reference & Reference \\
\hline \multicolumn{8}{|l|}{ Location of the DA } \\
\hline Metropolitan area & $38.52(.20)$ & $1.66(.00)$ & $10.58(.06)$ & $8.53(.02)$ & $15.24(.10)$ & $17.67(.05)$ & $2.74(.01)$ \\
\hline Small town & $19.93(.24)$ & $.90(.00)$ & $10.37(.07)$ & $6.15(.02)$ & $9.26(.12)$ & $4.98(.06)$ & $2.82(.01)$ \\
\hline Rural & Reference & Reference & Reference & Reference & Reference & Reference & Reference \\
\hline
\end{tabular}

${ }^{*}$ All variables are significant at the level of $P<.0001$.

there are more bars with video lottery terminals in the most socially deprived DAs.

\section{Discussion}

Alcohol outlets provide jobs and have a nonneglected contribution to the economy. Nevertheless, problematic behaviours and important social problems are associated presence of multiple outlets in a neighborhood. To our knowledge, few authors have examined the spatial accessibility of alcohol outlets either in Canada, or in any other developed country. There is a need to document the spatial location of alcohol outlets and the accessibility of neighborhoods to these outlets because it is well established that the availability of alcohol outlets has social consequences such as crime [5], heavy drinking behavior $[53,54]$, alcohol-related hospital admissions [55], and health problems [56,57]. Alcohol availability has also been shown as a predictor of youth drinking and driving [58]. The findings of the present study show that accessibility to alcohol outlets in Québec varies by neighborhood characteristics and accessibility is high in metropolitan and small towns. This seems normal given that these areas have the highest population concentration. In fact, it is obvious that owners of alcohol outlets prefer to locate their activity where demand is already high in order to capitalize on demand. Previous studies revealed that the highest clustering of outlets may promote lower prices through discounting and promotion of alcohol products which can entice buyers to consume liquor because of the attractively lower prices $[59,60]$.

One of the objectives of the study was to examine the relationship between neighborhood characteristics and the location of outlets. Some previous authors have reported a higher concentration of alcohol outlets in poor neighborhoods $[4,34,61]$. Their studies focused only on urban areas whereas the present study includes both rural and urban areas. This may explain in part why we found that whatever the threshold considered, outlets are more located in the most affluent materially deprived neighborhoods.

According to Statistics Canada [62], the prevalence of heavy drinking by age group and sex among Canadians aged 12 years and above in 2012 was $68.87 \%$ for men, $7.19 \%$ for persons aged 19 years and below, $43.3 \%$ among those aged 20-34, 17.16\% among 34-44 year olds, $27.39 \%$ for $45-64$ year olds, and $4.95 \%$ for those aged 65 years and above. The spatial location of outlets in Québec tends to follow this pattern. We hypothesized that reducing the density of alcohol outlets in these areas may reduce problematic drinking for these subgroups.

The association between materially deprived neighborhood and concentration of alcohol outlets is an important key finding of this study. Less materially deprived neighborhoods are characterised by an increased presence of restaurants and bar/brewery/tavern while material deprivation is positively associated with the density of off-premise outlets and of bars with lottery terminals. Authors called these two latter types of alcohol outlets "bad bars" because their activities generated neighborhood disturbances such as music and loitering in late hours of the night $[63,64]$. Literature indicates that these bad bars tend to be concentrated in crowded, highly dense and disorganized neighborhoods [63-65].

In one previous study on the accessibility of video lottery terminals (VLT) in Montreal, the authors found that VLTs were concentrated in the downtown area and in pericentral districts with the highest population density. They also found a positive correlation between accessibility to VLT and vulnerable neighborhoods [39]. The present study confirms these findings since the number of outlets with VLTs is greater in metropolitan areas followed by small towns. Also, social and material deprivations are positively correlated with the number of outlets with VLTs. 
4.1. Limitations and Strengths of the Study. The findings of this study should be considered in light of the following limitations. It is important to note that like many other studies of spatial accessibility, our method only concerns potential spatial accessibility, not revealed access (actual utilization of alcohol outlets). It is possible that residents in areas with high potential spatial accessibility (such as the inner city) may not actually enjoy good access to alcohol outlets because aspatial factors such as socioeconomic factors also play an important role in effective accessibility. Another limitation is the design of the study. Using a cross-sectional design, the present study only assesses the association between neighborhood characteristics and alcohol outlet density at a single point of time, which preclude inference on any causal relation. Further, it does not help in understanding if the neighborhood characteristics "attracted" a greater number of alcohol outlets or if the greater number of alcohol outlets impacted the neighborhoods' characteristics.

This study used neighborhood data from different year (2006) even if outlets data are from 2013. It was not possible to use census data of 2011 because major changes to the Canada census of 2011 greatly affected the validity of the data at fine spatial resolution (geographical scale) such as the one used here. We therefore used data for the previous census (2006) for characterising local areas while only the most recent data on alcohol outlets locations were available (2013; no archival data available). This temporal discrepancy is a limit of this study but we opine that the likelihood of bias is low. We have no data describing changes in neighborhoodlevel characteristics between 2006 and 2013 for the entire province of Québec. However, a study conducted in the Montreal metropolitan area, which encompasses approximately half of the Québec's population, showed that changes in neighbourhood-level SES were marginal between 1986 and 2006 [66].

We have used novel measures of alcohol accessibility and availability which enrich the prevalent notions of alcohol availability. The ability of GIS to handle large amounts of data over large geographic areas at fine levels of geographic detail makes it ideally suited to measure geographical accessibility to spatial facilities. The use of GIS facilitates the production of geographical accessibility measures that overcome the limitations of traditional statistics based on service-to-population ratio and Euclidian distances.

\section{Conclusion}

The findings of this study reveal that accessibility to alcohol outlets in Québec vary by the characteristics of the neighborhood and also by the type of alcohol outlet. Some specific types of alcohol outlets such as bars/breweries, restaurants and off-premises outlets are more accessible in neighborhoods with highest density of persons aged 20 to 34 years.

The results have shown that the potential spatial accessibility to alcohol outlets varies highly across the Province of Québec. For instance, there are about 16 alcohol outlets within a distance of 1 kilometre $(S D=10.2)$. Moreover, the outlet types more accessible at 1 kilometre are as follows: restaurant $($ mean $=5.8)$, off-premise $(5.27)$, bar/brewerytavern (2.87), and bar with video lottery terminal (1.43). Regarding factors associated with the availability of alcohol outlets, our results suggest that accessibility to alcohol outlets increases in metropolitan, least materially and high socially deprived neighborhoods.

Scientific literature indicates that the regulation of alcohol outlet density could be an effective means of controlling the social consequences of alcohol consumption [5, 29, 34, 67]. In Québec, as in other countries, there is no spatial restriction to obtaining a liquor permit. In other words, there is no restriction on the number of outlets per square kilometre or the number of outlets per 1,000 inhabitants within a radius of one kilometre. Given the relationship between outlet density and the multiple consequences in society, it may be possible to introduce restrictions on the number and density of outlets within a certain distance or to reduce the number of alcohol outlets in metropolitan areas and small towns.

Campbell et al. (2009) have proposed four types of alcohol outlet density regulations: these are geographic restrictions consisting in limiting the number of alcohol outlets per specific geographic unit, population-level restrictions by limiting the number of alcohol outlets per population so that the association between outlet density and alcohol consumption will follow the demand curve; commercial restrictions which aim is toestablish a cap on the percentage of retail alcohol outlets per total retail businesses in a geographic area and; the time/space restrictions which consists of limiting the location and operating hours of alcohol outlets [29]. Bans against alcoholic beverage which consists of reducing the density of alcohol outlets to zero has also been experimented in northern Canada and the southwestern U.S. [68-70].

\section{Conflict of Interests}

The authors declare that there is no conflict of interests regarding the publication of this paper.

\section{References}

[1] WHO, Global Status Report on Alcohol and Health, World Health Organization, Geneva, Switzerland, 2011.

[2] G. Thomas, Levels and Patterns of Alcohol Use in Canada. (Alcohol Price Policy Series: Report 1), Canadian Centre on Substance Abuse, Ottawa, Canada, 2012.

[3] F. I. Matheson, H. L. White, R. Moineddin, J. R. Dunn, and R. H. Glazier, "Drinking in context: the influence of gender and neighbourhood deprivation on alcohol consumption," Journal of Epidemiology and Community Health, vol. 66, no. 6, article e4, 2012.

[4] C. B. Cunradi, C. Mair, W. Ponicki, and L. Remer, "Alcohol outlets, neighborhood characteristics, and intimate partner violence: ecological analysis of a California city," Journal of Urban Health, vol. 88, no. 2, pp. 191-200, 2011.

[5] P. Day, G. Breetzke, S. Kingham, and M. Campbell, "Close proximity to alcohol outlets is associated with increased serious violent crime in New Zealand," Australian and New Zealand Journal of Public Health, vol. 36, no. 1, pp. 48-54, 2012. 
[6] A. Bryden, B. Roberts, M. McKee, and M. Petticrew, "A systematic review of the influence on alcohol use of community level availability and marketing of alcohol," Health and Place, vol. 18, no. 2, pp. 349-357, 2012.

[7] S. R. Dube, R. F. Anda, V. J. Felitti, J. B. Croft, V. J. Edwards, and W. H. Giles, "Growing up with parental alcohol abuse: exposure to childhood abuse, neglect, and household dysfunction," Child Abuse and Neglect, vol. 25, no. 12, pp. 1627-1640, 2001.

[8] A. M. Roche, K. Pidd, J. G. Berry, and J. E. Harrison, "Workers' drinking patterns: the impact on absenteeism in the Australian work-place," Addiction, vol. 103, no. 5, pp. 738-748, 2008.

[9] S. B. Bacharach, P. Bamberger, and M. Biron, "Alcohol consumption and workplace absenteeism: the moderating effect of social support," Journal of Applied Psychology, vol. 95, no. 2, pp. 334-348, 2010.

[10] E. Missoni, B. Božić, and I. Missoni, "Alcohol-related road traffic accidents before and after the passing of the Road Traffic Safety Act in Croatia," Collegium Antropologicum, vol. 36, no. 4, pp. 1483-1489, 2012.

[11] S. T. Bogstrand, H. Gjerde, P. T. Normann, I. Rossow, and $\varnothing$. Ekeberg, "Alcohol, psychoactive substances and non-fatal road traffic accidents-a case-control study," BMC Public Health, vol. 12, no. 1, article 734, 2012.

[12] T. Stübig, M. Petri, C. Zeckey et al., "Alcohol intoxication in road traffic accidents leads to higher impact speed difference, higher ISS and MAIS, and higher preclinical mortality," Alcohol, vol. 46, no. 7, pp. 681-686, 2012.

[13] C. Åslund and K. W. Nilsson, "Social capital in relation to alcohol consumption, smoking, and illicit drug use among adolescents: a cross-sectional study in Sweden," International Journal for Equity in Health, vol. 12, no. 1, article 33, 2013.

[14] R. Scribner, K. P. Theall, B. Ghosh-Dastidar, K. Mason, D. Cohen, and N. Simonsen, "Determinants of social capital indicators at the neighborhood level: a longitudinal analysis of loss of off-sale alcohol outlets and voting," Journal of Studies on Alcohol and Drugs, vol. 68, no. 6, pp. 934-943, 2007.

[15] E. L. Winstanley, D. M. Steinwachs, M. E. Ensminger, C. A. Latkin, M. L. Stitzer, and Y. Olsen, "The association of selfreported neighborhood disorganization and social capital with adolescent alcohol and drug use, dependence, and access to treatment," Drug and Alcohol Dependence, vol. 92, no. 1-3, pp. 173-182, 2008.

[16] S. Bullers, M. L. Cooper, and M. Russell, "Social network drinking and adult alcohol involvemen: a longitudinal exploration of the direction of influence," Addictive Behaviors, vol. 26, no. 2, pp. 181-199, 2001.

[17] S. M. Bot, R. C. M. E. Engels, R. A. Knibbe, and W. H. J. Meeus, "Friend's drinking behaviour and adolescent alcohol consumption: the moderating role of friendship characteristics," Addictive Behaviors, vol. 30, no. 5, pp. 929-947, 2005.

[18] S. Bellos, P. Skapinakis, D. Rai et al., "Cross-cultural patterns of the association between varying levels of alcohol consumption and the common mental disorders of depression and anxiety: secondary analysis of the WHO Collaborative Study on Psychological Problems in General Health Care," Drug and Alcohol Dependence, vol. 133, no. 3, pp. 825-831, 2013.

[19] K. A. Welch and C. Derry, "Mild traumatic brain injury and epilepsy: alcohol misuse may underpin the association," Journal of Neurology, Neurosurgery and Psychiatry, vol. 85, no. 6, p. 593, 2014.

[20] A. Higashiyama, T. Okamura, M. Watanabe et al., "Alcohol consumption and cardiovascular disease incidence in men with and without hypertension: the Suita study," Hypertension Research, vol. 36, no. 1, pp. 58-64, 2013.

[21] M. Ohsawa and K. Tanno, "Conflicting effect of alcohol on cardiovascular risk: a clue to understand the different etiologies of coronary artery disease, stroke and peripheral artery disease," Hypertension Research, vol. 36, no. 1, pp. 16-18, 2013.

[22] S. L. Au Yeung, C. Jiang, K. K. Cheng et al., "Moderate alcohol use and cardiovascular disease from Mendelian randomization," PLoS ONE, vol. 8, no. 7, Article ID e68054, 2013.

[23] G. Testino, V. Patussi, E. Scafato, O. Ancarani, and P. Borro, "Alcohol, cardiovascular disease and cancer," Alcohol and Alcoholism, vol. 48, no. 5, pp. 627-628, 2013.

[24] C. Scoccianti, K. Straif, and I. Romieu, "Recent evidence on alcohol and cancer epidemiology," Future Oncology, vol. 9, no. 9, pp. 1315-1322, 2013.

[25] J. Rehm, T. K. Greenfield, and J. D. Rogers, "Average volume of alcohol consumption, patterns of drinking, and all-cause mortality: results from the US national alcohol survey," American Journal of Epidemiology, vol. 153, no. 1, pp. 64-71, 2001.

[26] R. Lambert, N. April, R. Morin, and C. Bégin, Alcohol Consumption and Public Health in Québec: Summary, Institut National de Santé Publique du Québec, Québec, Canada, 2013.

[27] E. R. Weitzman, A. Folkman, M. P. H. K. L. Folkman, and H. Wechsler, "The relationship of alcohol outlet density to heavy and frequent drinking and drinking-related problems among college students at eight universities," Health and Place, vol. 9, no. 1, pp. 1-6, 2003.

[28] F. J. Chaloupka and H. Wechsler, "Binge drinking in college: the impact of price, availability, and alcohol control policies," Contemporary Economic Policy, vol. 14, no. 4, pp. 112-124, 1996.

[29] C. A. Campbell, R. A. Hahn, R. Elder et al., "The effectiveness of limiting alcohol outlet density as a means of reducing excessive alcohol consumption and alcohol-related harms," American Journal of Preventive Medicine, vol. 37, no. 6, pp. 556-569, 2009.

[30] R. N. Bluthenthal, D. A. Cohen, T. A. Farley et al., "Alcohol availability and neighborhood characteristics in Los Angeles, California and Southern Louisiana," Journal of Urban Health, vol. 85, no. 2, pp. 191-205, 2008.

[31] R. Young, L. Macdonald, and A. Ellaway, "Associations between proximity and density of local alcohol outlets and alcohol use among Scottish adolescents," Health \& Place, vol. 19, no. 1, pp. 124-130, 2013.

[32] C. Wilkinson and M. Livingston, "Distances to on- and offpremise alcohol outlets and experiences of alcohol-related amenity problems," Drug and Alcohol Review, vol. 31, no. 4, pp. 394-401, 2012.

[33] C. E. Pollack, C. Cubbin, D. Ahn, and M. Winkleby, "Neighbourhood deprivation and alcohol consumption: does the availability of alcohol play a role?" International Journal of Epidemiology, vol. 34, no. 4, pp. 772-780, 2005.

[34] G. C. Hay, P. A. Whigham, K. Kypri, and J. D. Langley, "Neighbourhood deprivation and access to alcohol outlets: a national study," Health and Place, vol. 15, no. 4, pp. 1086-1093, 2009.

[35] A. Ellaway, L. Macdonald, A. Forsyth, and S. Macintyre, "The socio-spatial distribution of alcohol outlets in Glasgow city," Health \& Place, vol. 16, no. 1, pp. 167-172, 2010.

[36] R. J. Sampson and R. B. Groves, "Community structure and crime: testing social disorganization theory," American Journal of Sociology, vol. 94, no. 4, pp. 774-802, 1989. 
[37] B. Kingston, D. Huizinga, and D. S. Elliott, "A Test of social disorganization theory in high-risk urban neighborhoods," Youth and Society, vol. 41, no. 1, pp. 53-79, 2009.

[38] http://www.stat.gouv.qc.ca/statistiques/population-demographie/structure/index.html.

[39] É. Robitaille and P. Herjean, "An analysis of the accessibility of video lottery terminals: the case of Montréal," International Journal of Health Geographics, vol. 7, article 2, 2008.

[40] Statistiques Canada, Dictionnaire du Recensement de 2006, M.d. l'Industrie, Ottawa, Canada, 2010.

[41] R. Pampalon, D. Hamel, P. Gamache, M. D. Philibert, G. Raymond, and A. Simpson, "An area-based material and social deprivation index for public health in Québec and Canada," Canadian Journal of Public Health, vol. 103, supplement 2, pp. S17-S22, 2012.

[42] R. Pampalon, D. Hamel, P. Gamache, and G. Raymond, "A deprivation index for health planning in Canada," Chronic Diseases in Canada, vol. 29, no. 4, pp. 178-191, 2009.

[43] http://www12.statcan.gc.ca/census-recensement/2011/ref/dict/ geo045-eng.cfm.

[44] A. Ngamini Ngui, A. A. Cohen, J. Courteau et al., "Does elapsed time between first diagnosis of schizophrenia and migration between health territories vary by place of residence? A survival analysis approach," Health and Place, vol. 20, pp. 66-74, 2013.

[45] P. Apparicio, M. Abdelmajid, M. Riva, and R. Shearmur, "Comparing alternative approaches to measuring the geographical accessibility of urban health services: distance types and aggregation-error issues," International Journal of Health Geographics, vol. 7, article 7, 2008.

[46] http://adressesquebec.gouv.qc.ca/aqreseau.asp.

[47] J. McDonald and R. Moffit, "The uses of tobit analysis," The Review of Economic Studies, vol. 62, no. 2, pp. 318-321, 1980.

[48] L. Sigelman and L. Zeng, "Analyzing censored and sampleselected data with Tobit and Heckit models," Political Analysis, vol. 8, no. 2, pp. 167-182, 1999.

[49] W. Greene, Econometric Analysis, Prentice Hall, Upper Saddle River, NJ, USA, 4th edition, 2000.

[50] J. J. Heckman, "Sample selection bias as a specification error," Econometrica, vol. 47, no. 1, pp. 153-161, 1979.

[51] B. G. Tabachnick and L. S. Fidell, Using Multivariate Statistics, vol. 5, Pearson Education, New York, NY, USA, 2007.

[52] P. C. Austin, M. Escobar, and J. A. Kopec, "The use of the Tobit model for analyzing measures of health status," Quality of Life Research, vol. 9, no. 8, pp. 901-910, 2000.

[53] B. A. Reboussin, J. S. Preisser, E.-Y. Song, and M. Wolfson, "Geographic clustering of underage drinking and the influence of community characteristics," Drug and Alcohol Dependence, vol. 106, no. 1, pp. 38-47, 2010.

[54] T. Huckle, J. Huakau, P. Sweetsur, O. Huisman, and S. Casswell, "Density of alcohol outlets and teenage drinking: living in an alcogenic environment is associated with higher consumption in a metropolitan setting," Addiction, vol. 103, no. 10, pp. 16141621, 2008.

[55] J. R. Tatlow, J. D. Clapp, and M. M. Hohman, "The relationship between the geographic density of alcohol outlets and alcoholrelated hospital admissions in San Diego County," Journal of Community Health, vol. 25, no. 1, pp. 79-88, 2000.

[56] G. Pereira, L. Wood, S. Foster, and F. Haggar, "Access to alcohol outlets, alcohol consumption and mental health," PLoS ONE, vol. 8, no. 1, Article ID e53461, 2013.
[57] J. M. Major, J. D. Sargent, B. I. Graubard et al., "Local geographic variation in chronic liver disease and hepatocellular carcinoma: contributions of socioeconomic deprivation, alcohol retail outlets, and lifestyle," Annals of Epidemiology, vol. 24, no. 2, pp. 104110, 2014.

[58] A. J. Treno, J. W. Grube, and S. E. Martin, "Alcohol availability as a predictor of youth drinking and driving: a hierarchical analysis of survey and archival data," Alcoholism: Clinical and Experimental Research, vol. 27, no. 5, pp. 835-840, 2003.

[59] M. Livingston, T. Chikritzhs, and R. Room, "Changing the density of alcohol outlets to reduce alcohol-related problems," Drug and Alcohol Review, vol. 26, no. 5, pp. 557-566, 2007.

[60] B. A. Reboussin, E.-Y. Song, and M. Wolfson, “The impact of alcohol outlet density on the geographic clustering of underage drinking behaviors within census tracts," Alcoholism: Clinical and Experimental Research, vol. 35, no. 8, pp. 1541-1549, 2011.

[61] B. A. Reboussin, E. Y. Song, and M. Wolfson, "The impact of alcohol outlet density on the geographic clustering of underage drinking behaviors within census tracts," Alcoholism: Clinical and Experimental Research, vol. 35, no. 8, pp. 1541-1549, 2011.

[62] http://www.statcan.gc.ca/tables-tableaux/sum-som/101/cst01/ health79a-eng.htm.

[63] K. Graham, S. Bernards, D. W. Osgood, and S. Wells, "Bad nights or bad bars? Multi-level analysis of environmental predictors of aggression in late-night large-capacity bars and clubs," Addiction, vol. 101, no. 11, pp. 1569-1580, 2006.

[64] J. Green and M. A. Plant, "Bad bars: a review of risk factors," Journal of Substance Use, vol. 12, no. 3, pp. 157-189, 2007.

[65] D. R. Thomas and C. Byrne, "Attitudes towards taverns in three Hamilton suburbs," Man-Environment Systems, vol. 10, pp. 197202, 1980.

[66] A.-M. Séguin, P. Apparicio, and M. Riva, "Identifying, mapping and modelling trajectories of poverty at the neighbourhood level: the case of Montréal, 1986-2006," Applied Geography, vol. 35, no. 1-2, pp. 265-274, 2012.

[67] J. L. Connor, K. Kypri, M. L. Bell, and K. Cousins, "Alcohol outlet density, levels of drinking and alcohol-related harm in New Zealand: a national study," Journal of Epidemiology \& Community Health, 2010.

[68] R. Baughman, M. Conlin, S. Dickert-Conlin, and J. Pepper, "Slippery when wet: the effects of local alcohol access laws on highway safety," Journal of Health Economics, vol. 20, no. 6, pp. 1089-1096, 2001.

[69] C. M. Davison, C. S. Ford, P. A. Peters, and P. Hawe, "Community-driven alcohol policy in Canada's northern territories 1970-2008," Health Policy, vol. 102, no. 1, pp. 34-40, 2011.

[70] P. May, "Arrests, alcohol and alcohol legalization among an American Indian tribe," Plains Anthropologist, vol. 20, no. 68, pp. 129-134, 1975. 


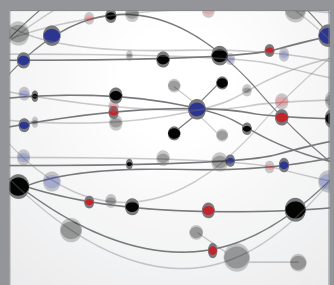

The Scientific World Journal
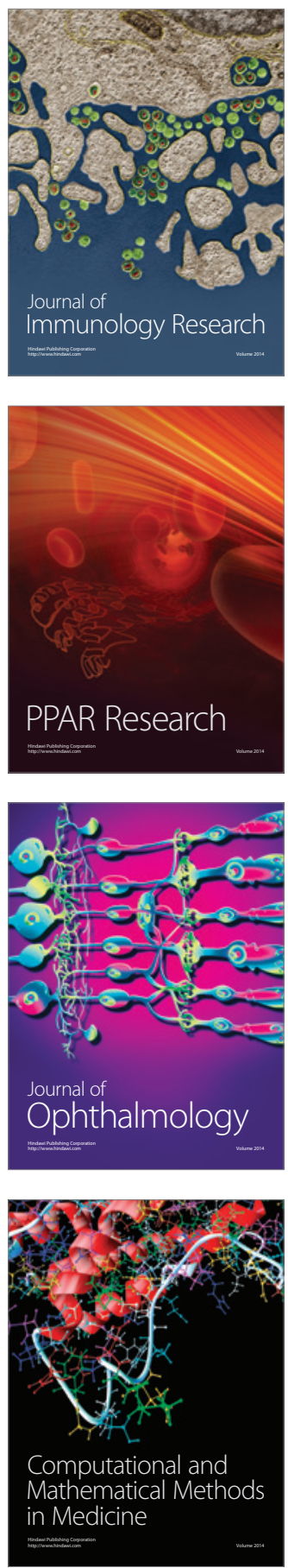

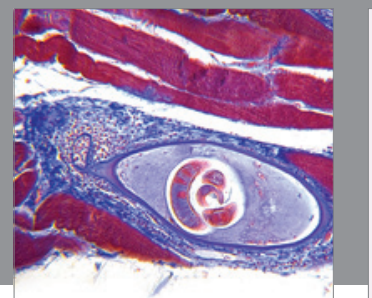

Gastroenterology

Research and Practice
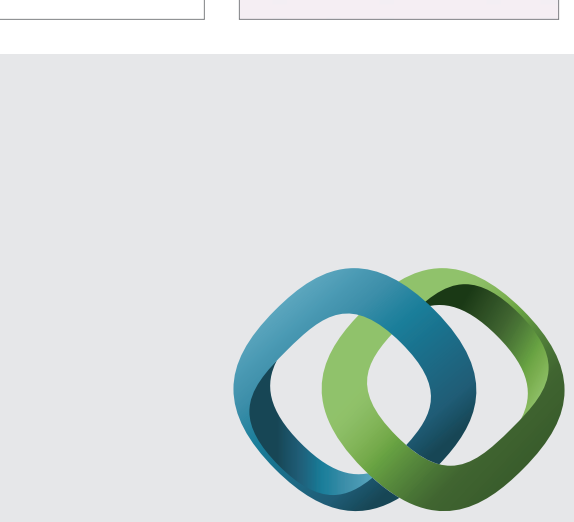

\section{Hindawi}

Submit your manuscripts at

http://www.hindawi.com
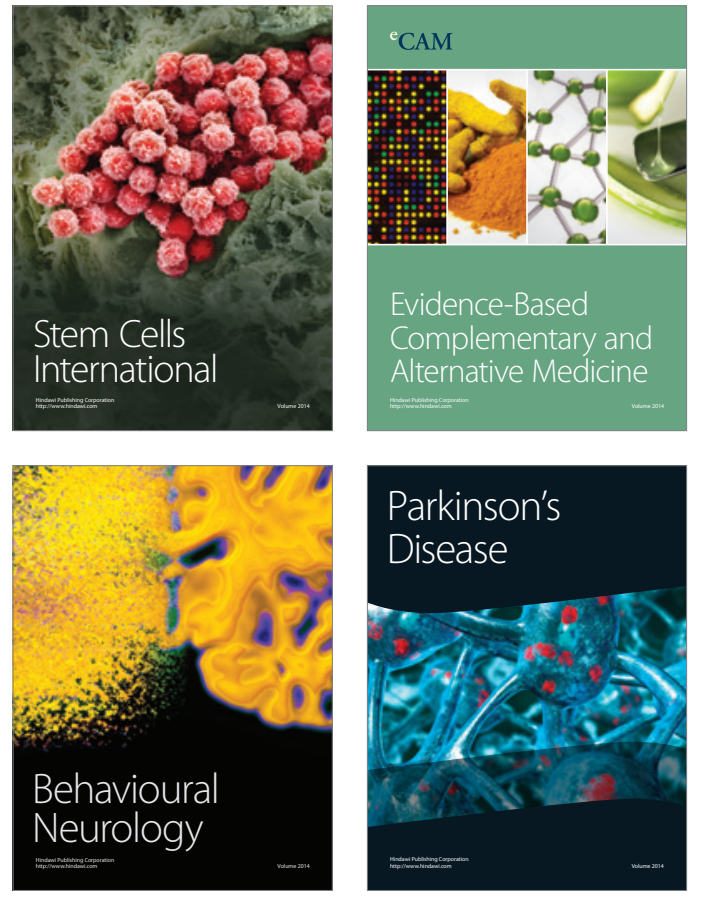
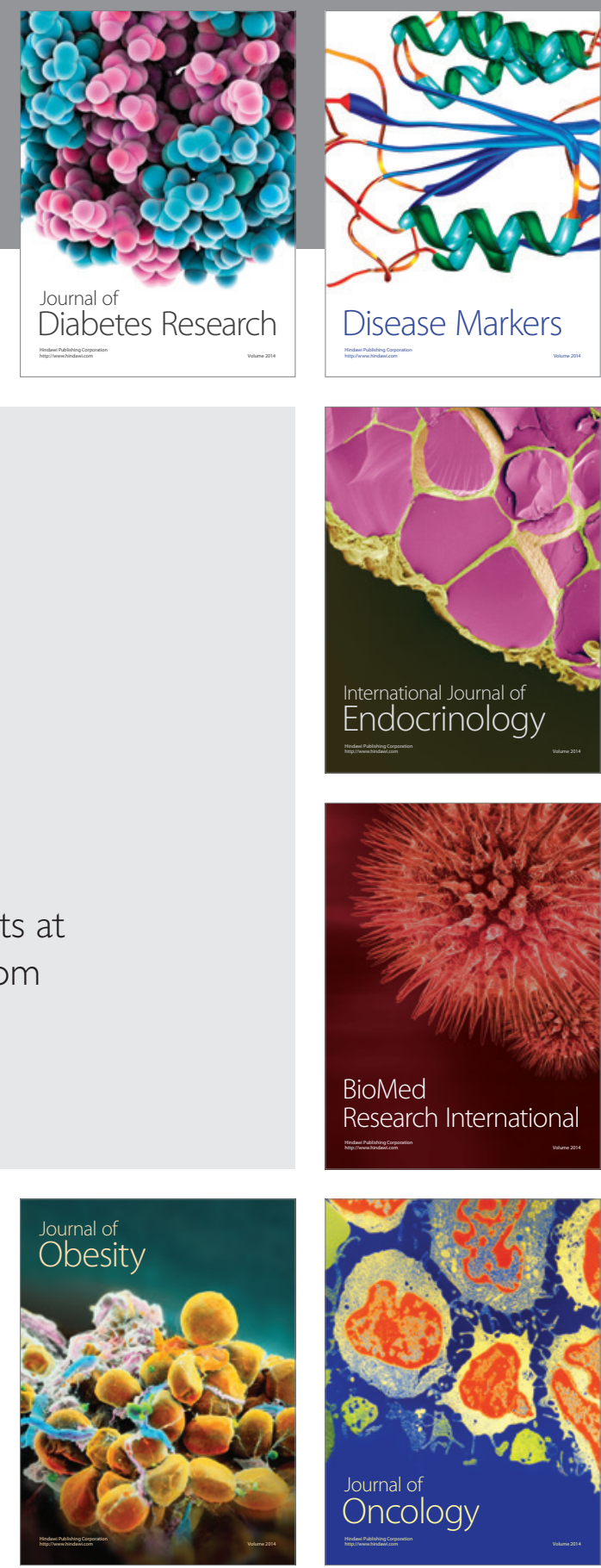

Disease Markers
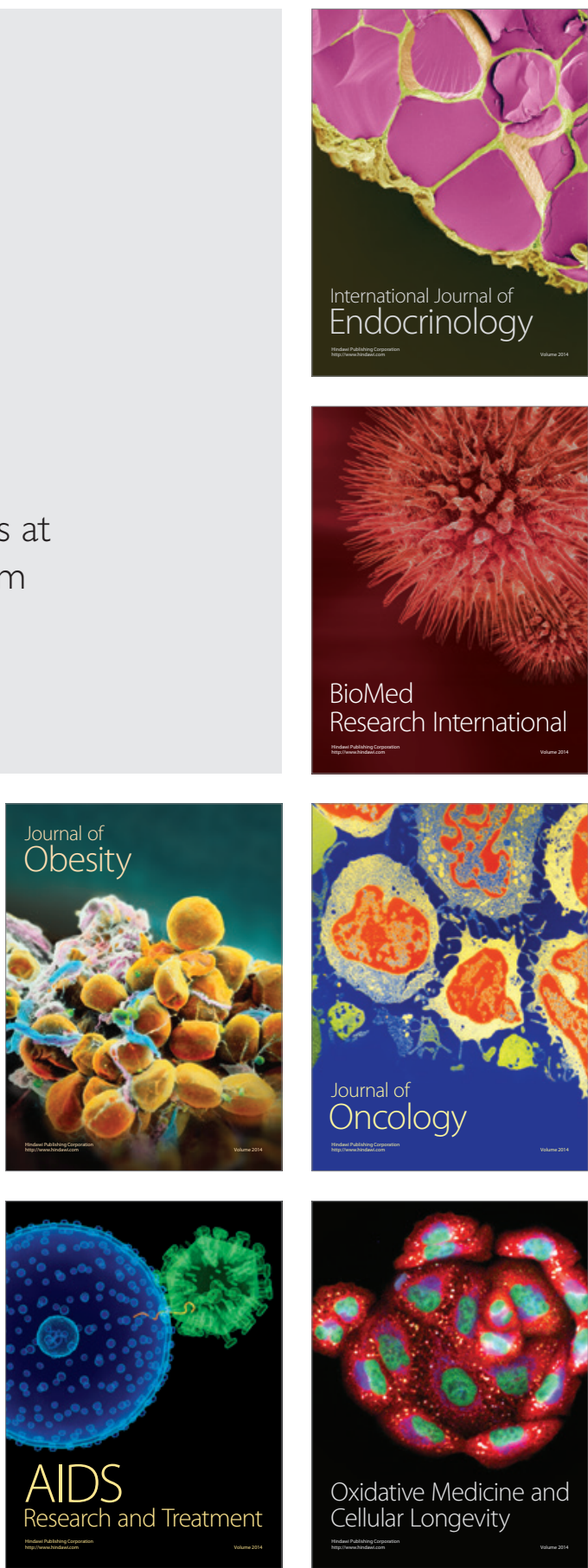